Int. J. Dev. Biol. 53: 245-257 (2009)

doi: $10.1387 / \mathrm{ijdb} .082691 \mathrm{av}$

\title{
Common themes in siRNA-mediated epigenetic silencing pathways
}

\author{
ANDRÉ VERDEL* AURÉLIA VAVASSEUR, MADALEN LE GORREC and LEILA TOUAT-TODESCHINI \\ Institut National de la Santé et de la Recherche Médicale (INSERM) U823 and \\ Université Joseph Fourier, Institut Albert Bonniot, Faculté de Médecine, Grenoble, France
}

\begin{abstract}
Small interfering RNAs (siRNAs) act through RNA interference (RNAi) pathways to silence gene expression either at the transcriptional or post-transcriptional level. Here, we review mechanisms and functions of siRNA-mediated silencing pathways that promote chromatin modifications in the fission yeast Schizosaccharomyces pombe, plants and animals. In fission yeast, siRNAs are involved in heterochromatin formation and key aspects of the underlying siRNAdependent pathway have been uncovered. Two RNAi complexes, the RNA-Induced Transcriptional Silencing complex (RITS), which contains a siRNA bound to an Argonaute protein, and the RNA-Directed RNA polymerase Complex (RDRC) are critical components of the pathway. In addition, this pathway implicates non-coding nascent transcripts synthesized by RNA polymerase II (RNApII) and the RNApll itself. In Arabidopsis thaliana, the RNA-directed DNA methylation (RdDM) pathway appears to share a similar set of proteins and enzymatic activities, suggesting that, beyond certain aspects that are specific to each pathway, part of the siRNA-mediated epigenetic silencing mechanisms are conserved between fission yeast and plants. Moreover, in both organisms the pathways target repetitive DNA sequences. This conservation of mechanisms and genomic targets might actually extend to animals as recent investigations revealed the existence of endogenous siRNA-based pathways directed against repetitive DNA sequences in flies and mammals.
\end{abstract}

KEY WORDS: siRNA, RNAi, gene silencing, epigenetics, heterochromatin

\section{Introduction}

Just over a decade ago, Fire, Mello and colleagues discovered that micro-injection of long double-stranded RNA (dsRNA) into Caenhorbditis elegans worms triggered a potent and sequencespecific gene silencing or RNA interference (RNAi) (Fire et al., 1998; Mello and Conte, 2004). It was rapidly found that small RNA molecules of 21 to 25 nucleotides, termed small interfering RNAs (siRNAs), are the molecules that convey RNAi sequence-specificity (Mello and Conte, 2004). SiRNA-mediated silencing has now been observed in the vast majority of the eukaryotes studied (with the noticeable exception of the yeast Saccharomyces cerevisiae), is widely used to analyze the function of proteins by knocking down their expression, and offers the promise of new therapeutic strategies (de Fougerolles et al., 2007; Mello and Conte, 2004).

Besides siRNAs, two other major species of small RNAs, the micro RNAs (miRNAs) and the Piwi-associated RNAs (piRNAs), have been shown to also act through RNAi or RNAi-related pathways. These three small RNA species can be distinguished based on their biogenesis and length, the identity of their Argonaute partner and their associated-mechanism of gene silencing. Argonaute proteins form a superfamily composed of the Argonaute and the Piwi clades. MiRNAs, like siRNAs, are generated from double stranded RNA through a "dicing" catalyzed by the Dicer nuclease, are of similar size and bind members of the Argonaute clade. However, unlike siRNAs, miRNAs do not originate from double-stranded RNAs formed by the hybridization of two complementary RNAs. MiRNAs are generated from RNA molecules that individually form small hairpin RNA structures of $\sim 70$ nucleotides

Abbreviations used in this paper:RDRC, RNA-directed RNA polymerase complex; RdDM, RNA-directed DNA methylation; RITS, RNA-induced transcriptional silencing complex; RNAi, RNA interference; RNApII, RNA polymerase II; siRNA, small interfering RNA; TGS, transcriptional gene silencing.

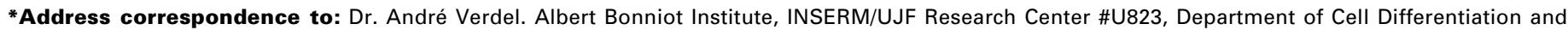
Transformation, Domaine de la Merci, 38706, La Tronche Cedex, France.

Fax: + 33-4-7554-9595. e-mail: andre.verdel@ujf-grenoble.fr - web: http://www-iab.ujf-grenoble.fr
}

Published online: 21 April 2009.

ISSN: Online 1696-3547, Print 0214-6282 
Fig. 1. (A) Post-transcriptional and (B) transcriptional siRNA-mediated silencing pathways. Both pathways are activated by the detection of long dsRNAs by the RNAi machinery. DsRNAs are processed by Dicer ribonucleases (Dcr) into siRNA duplexes that then bind to Argonaute (Ago) proteins. Together with the siRNA, Ago proteins form the core of RNAi effector complexes (RISC and RITS). One strand of the incorporated doublestranded siRNA is eliminated (the passenger strand) whereas the other strand (the guide strand) is used to recognize the target RNA. Perfect base-pairing between the guide strand and the target RNA allows the cleavage of the target. Thus, both PTGS and TGS pathways share a common set of mechanisms and enzymatic activities (highlighted by the central large arrow). Nonetheless, the silencing induced by both pathways shows major distinctions. In the post-transcriptional gene silencing (PTGS), siRNAs direct mRNA degradation in the cytoplasm with no epigenetic incidence, as they do not act directly on the

A

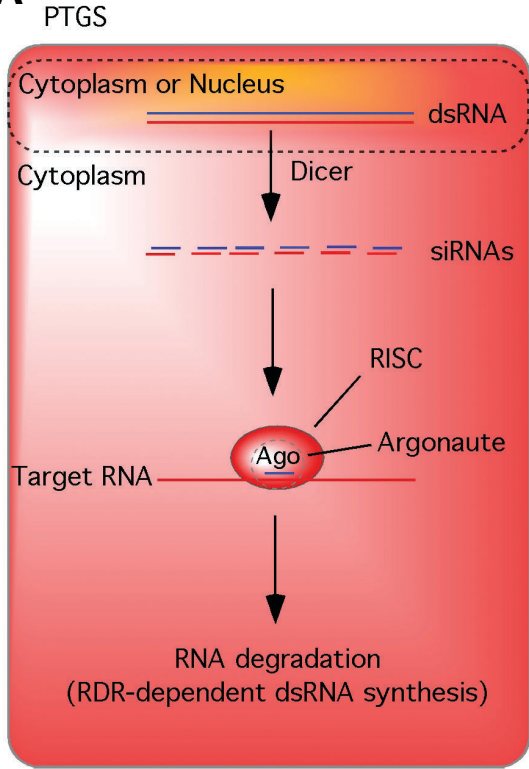

B

TGS

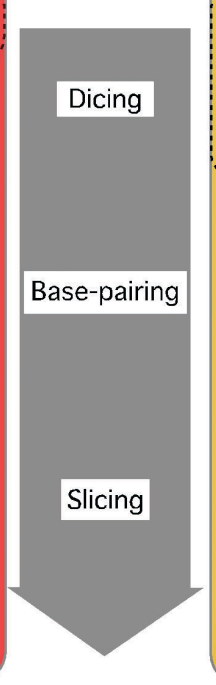

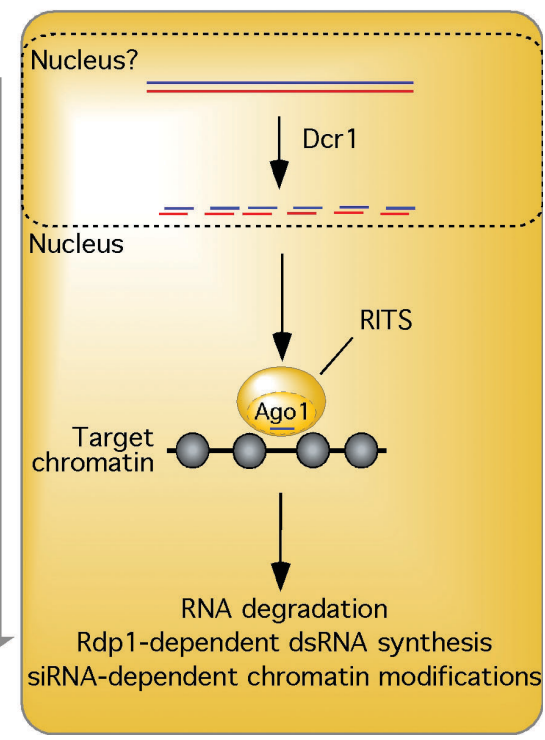

transcription rate of the corresponding gene. On the contrary, siRNA-mediated transcriptional gene silencing (TGS) acts in the nucleus and comes with chromatin modifications that silence transcription and that can be maintained throughout mitosis and meiosis, thus maintaining silencing over multiple generations. Note that the PTGS pathway is illustrated with the generic names of protein and complexes, whereas for the TGS pathway the fission yeast names are mentioned. RISC, RNA-Induced Silencing Complex; RITS, RNA-Induced Transcriptional Silencing complex; Grey circles represent nucleosomes.

(Bartel, 2004). Once loaded onto RNAi effector complexes, the miRNA sequence allows the RNAi complex to base-pair with target mRNAs, but unlike siRNAs, the miRNA sequence often presents several mismatches with its target. Moreover, for most of the organisms studied, the miRNA induces a silencing at the posttranscriptional level in the cytoplasm that consists in inhibiting translation, whereas siRNAs can act in the nucleus directly on the gene. PiRNAs have been discovered more recently (Aravin et al., 2007). Their generation does not depend on Dicer, they have a longer average size of 28 to 33 nucleotides and, conversely to siRNAs and miRNAs that bind proteins from the Argonaute clade, piRNAs bind Piwi clade proteins. It is becoming clear that piRNAs play an important role in limiting the mobility of transposons in germline cells (Aravin et al., 2007). Although animals contain both siRNAs and piRNAs, other organisms like fission yeast and plants appear to only produce siRNAs and do not express Argonaute proteins from the Piwi clade.

Here, we focus on the mechanisms and functions of siRNAmediated chromatin modifications observed mainly in fission yeast, plants and animals. The role of siRNAs and new RNAi complexes in heterochromatin formation, as well as the unexpected implication of RNA polymerase II (RNApII) transcription are first reviewed in fission yeast. Through the description of plant RNA-directed DNA methylation (RdDM) and mammalian siRNA-directed transcriptional gene silencing (TGS), we then point out similarities between these siRNA-dependent chromatin modification pathways. We also discuss the known and possible functions of these pathways, some of which have important developmental roles.

\section{Nuclear siRNA-dependent gene silencing}

SiRNA-dependent pathways can act in the nucleus and the cytoplasm by mediating, respectively, TGS and post-transcrip- tional gene silencing (PTGS). In both situations, a similar set of steps is engaged from the activation of the pathway to the siRNAdependent silencing of gene expression (Fig. 1). SiRNA-mediated silencing pathways are activated by double-stranded RNAs that are processed into siRNAs by Dicer, a type III ribonuclease. SiRNAs are then incorporated onto RNAi effector complexes that use the siRNA sequence as a specificity determinant to associate only with complementary RNA. The RNAi-Induced Silencing Complex (RISC) and the RNAi-Induced Transcriptional Silencing (RITS) complex mediate, respectively, siRNA-dependent PTGS and TGS. Both type of complexes contain an Argonaute protein but, conversely to RISC, RITS appears to localize exclusively in the nucleus and to contain at least one chromatin-binding module, the chromodomain (Fig. 1). Once a perfect match occurs between the siRNA and a targeted RNA, the latter is cleaved. In fission yeast, Neurospora crassa, Caenorhabditis elegans and plants, RNAdirected RNA polymerases (RDR) amplify this silencing response by using the target RNA as a template to synthesize more dsRNAs that fuel the siRNA pathway and amplify the siRNA-mediated silencing. Fly and vertebrate genomes do not possess genes encoding proteins homologous to RDRs, indicating that these organisms might do without this RDR amplification step. Another major distinction between nuclear and cytoplasmic siRNA-mediated silencing pathways is that in the first instance siRNAs can trigger a long term and heritable gene silencing which is maintained in an epigenetic fashion.

\section{Fission yeast siRNA-dependent heterochromatin for- mation}

Conserved proteins and post-translational modifications in heterochromatin formation

Fission yeast has proven to be a powerful biological system to 
study heterochromatin assembly (Allshire and Selker, 2007; Grewal and Moazed, 2003). It possesses relatively large domains of constitutive heterochromatin present at pericentromeric and subtelomeric regions, as well as at the mating type interval, a genomic region with an important developmental function as it controls yeast cellular identity. Formation and propagation of heterochromatin at all these sites involve a set of histone-modifying enzymes, histone marks and histone-binding proteins, conserved in the great majority of eukaryotes. Histone-modifying enzymes include a member from all three classes of eukaryotic histone deacetylases (HDAC), Clr3, Clr6 and Sir2, and a histone methyltransferase, Clr4, the yeast counterpart of Drosophila melanogaster and mammalian SU(VAR)3-9. Clr4 catalyzes methylation of histone $\mathrm{H} 3$ lysine 9 (H3K9me), a histone mark essential for establishment and maintenance of heterochromatin assembly. It is believed that $\mathrm{H} 3 \mathrm{~K} 9$ me serves as a docking site for chromodomain proteins such as Swi6 and Chp2, which are both homologues of the vertebrates heterochromatin proteins 1 (HP1). Another chromodomain protein, Chp1, also binds to H3K9me and is essential for heterochromatin formation. It has been proposed that, once bound to an H3K9me modified nucleosome, Swi6 recruits Clr4 and possibly other chromatin-modifying enzymes to initiate a new cycle of H3K9 methylation and histone-binding onto adjacent nucleosomes (Grewal and Jia, 2007; Grewal and Rice, 2004). This Swi6based recruitment mechanism might also be responsible for the observed epigenetic maintenance of heterochromatin through mitotic and meiotic divisions.

\section{Role of RNAi in heterochromatin formation}

Fission yeast presents the particularity to possess a "canonical" RNAi pathway (Fig. 1) with little or no redundancy among the main actors. Key RNAi proteins such as Dcr1, a Dicer RNAse III enzyme that cleaves dsRNA into siRNAs, Ago1, a member of the Argonaute family of proteins that bind siRNAs, and Rdp1, a RNAdirected RNA polymerase, are all encoded by single copy genes. Experiments based on deletion of $d c r 1$, ago1 and $r d p 1$ genes have pointed to a direct role of RNAi in the formation of pericentromeric heterochromatin and thus in the function of centromeres in fission yeast (Volpe et al., 2003; Volpe et al., 2002). Forward and reverse strands of pericentromeric DNA repeats are transcribed and the resulting non-coding RNAs accumulate in RNAi-deficient strains as the transcriptional silencing is relieved. On a mechanistic point of view, transcription from both strands of pericentromeric DNA was proposed to permit the formation of dsRNA that are processed into siRNAs by RNAi (Volpe et al., 2002). The detection and cloning of siRNAs complementary to pericentromeric DNA support such possibility (Cam et al., 2005; Reinhart and Bartel, 2002; Verdel et al., 2004).

Besides centromeres, RNAi also participates in the formation of heterochromatin at the mating type interval and the subtelomeric regions. In fission yeast, these main heterochromatic regions share DNA sequences of several hundred nucleotides that are more than 96\% identical (Wood et al., 2002). Genetic manipulations consisting in integrating portions of the shared DNA sequences into euchromatic regions have demonstrated that these sequences are nucleation centers for RNAi-mediated heterochromatin formation, and thus suggested a broad implication of RNAi in heterochromatin formation in fission yeast (Hall et al., 2002; Sadaie et al., 2004). The RNAi proteins Ago1 and Rdp1 have been found associated with every major heterochromatic loci, by site-specific and genome-wide chromatin immunoprecipitation (ChIP) experiments, which confirmed the suspected wide-spread implication of RNAi in heterochromatin formation in fission yeast (Cam et al., 2005; Noma et al., 2004; Sugiyama et al., 2005).

Deletion of $d c r 1$, ago 1 or rdp1 does not disrupt heterochromatin formation and transcriptional silencing at the mating-type interval and telomeres (Hall et al., 2002; Petrie et al., 2005). This important distinction with centromeres is due to a pathway that acts in parallel of RNAi to form heterochromatin at these loci. At the mating-type domain, two transcription factors of the ATF/ CREB family, Atf1 and Pcr1, bind DNA consensus sequences present in the DNA element REIII (Jia et al., 2004a, Kim et al., 2004). Inactivation of either RNAi or Atf1/Pcr1 transcription factors has no significant repercussion on mating-type heterochromatin maintenance, whereas combination of both mutations leads to a dramatic loss of heterochromatin (Jia et al., 2004a, Kim et al., 2004). The exact mechanism by which Atf1 and Pcr1 mediate formation of heterochromatin is currently unknown but these transcription factors might actually directly recruit the heterochromatin formation machinery, as they both interact with Swi6 and Clr4 (Jia et al., 2004a, Kim et al., 2004). Similarly at telomeres, Taz1 a protein that recognizes telomeric DNA repeats also nucleates heterochromatin formation in a RNAi-independent manner (Hansen et al., 2006; Kanoh et al., 2005).

Is RNAi important for heterochromatin establishment, maintenance or both? In fission yeast, establishment of heterochromatin assembly can be studied after a complete erasure of heterochromatin marks provoked by the inactivation of clr4 gene or by the use of Trichostatin A (TSA), a potent inhibitor of class I and II HDACs. Reintroduction of clr4 or growth in a fresh medium without TSA leads to reformation of heterochromatin. In atf1 or pcr1 deficient strains, heterochromatin formation at the matingtype is efficiently reestablished in a RNAi-dependent manner (Hall et al., 2002; Jia et al., 2004a). Conversely, in dcr1, rdp1 and ago1 mutant strains, a moderate reestablishment of heterochromatin formation is also observed. Thus, RNAi and to a lesser extent Atf1/Pcr1 transcription factors, can separately establish heterochromatin formation.

At centromeres, RNAi is required for efficient maintenance of heterochromatin formation (Hall et al., 2002; Verdel et al., 2004; Volpe et al., 2003; Volpe et al., 2002). At the mating-type interval, RNAi is also required for maintenance of heterochromatin but only if either atf1 or pcr1 gene is inactivated (Hall et al., 2002; Jia et al., $2004 b)$. An intriguing aspect that currently remains obscure is whether RNAi-dependent and -independent maintenance of heterochromatin structure call upon similar mechanisms. It might be that in the case of the RNAi-dependent pathway maintenance consists of a continuous reestablishment of heterochromatin formation, which would contrasts with the classical view of silent chromatin being a relatively static chromatin structure.

\section{RITS and RDRC RNAi complexes}

Purification and characterization of fission yeast RNAi complexes essential for heterochromatin assembly has provided important insights into the mechanisms of the fission yeast siRNA-dependent heterochromatin formation pathway. Early experiments indicated that the chromodomain protein Chp1 is essential for heterochromatin formation and acts early in this 
process (Partridge et al., 2002). The following purification of Chp1 led to the identification of the first RNAi effector complex to be directly involved in chromatin modification, and known as the RNA Induced Transcriptional Silencing (RITS) complex (Verdel et al., 2004; Verdel and Moazed, 2005).

RITS is formed of three proteins, Chp1, Ago1 and Tas3 (Verdel et al., 2004), a protein that has been recently found to bridge Chp1 to Ago1 (Debeauchamp et al., 2008; Partridge et al., 2007). RITS also contains siRNAs that bind Ago1 (Verdel et al., 2004). Deletion of either chp1, tas3 or ago1 gene disrupts pericentromeric heterochromatin formation and relieves the transcriptional gene silencing of a reporter gene integrated in a heterochromatic region, indicating that RITS is required for heterochromatin formation and gene silencing at centromeres. In parallel, RITS has been found to associate with heterochromatin in a Dcr1-dependent manner by ChIP experiments, suggesting that siRNAs might direct RITS to specific chromatin regions. The facts that siRNAs are not critical for RITS formation or stability, and that RITSassociated siRNAs match heterochromatic DNA sequences have further strengthened a direct implication of siRNAs in targeting RITS to chromatin (Verdel et al., 2004).

Rdp1 was initially found to associate with heterochromatin, suggesting that a RDR might be directly implicated in siRNAmediated heterochromatin formation in fission yeast (Volpe et al., 2002). This was confirmed by the purification of Rdp1, which led to the identification of a second RNAi complex termed RNADirected RNA polymerase Complex (RDRC) (Motamedi et al., 2004). RDRC is formed by the association of Rdp1 with Hrr1, a putative RNA helicase, and Cid12, a member of an atypical family of poly(A)-polymerase. Like RITS, every subunits of RDRC are critical for formation of heterochromatin at centromeres. Close analyses of Rdp1 mutants have demonstrated that Rdp1 is responsible for RDRC's in vitro RNA-directed RNA polymerase activity, and that in vivo this RDR activity is necessary for RNAidependent heterochromatin assembly (Motamedi et al., 2004; Sugiyama et al., 2005). Importantly, an interaction between RDRC and RITS was uncovered by a combination of mass spectrometry analyses on purified RDRC and coimmunoprecipitation experiments. This physical connection between RITS and RDRC has greatly helped to figure out the role and position of RDRC in the siRNA-dependent heterochromatin formation pathway (Motamedi et al., 2004). RITS-RDRC interaction requires the $\mathrm{H} 3 \mathrm{~K} 9$ me methyltransferase $\mathrm{Cl} 4$, which implies that RITS and RDRC are likely to bind each other only in a heterochromatic environment. Furthermore, and quite unexpectedly, inactivation of any subunit of RDRC has been correlated to no more detection of siRNAs incorporated into RITS, indicating that RDRC might act early in the siRNA-dependent heterochromatin formation pathway.

\section{The RNA platform model and the transcription within hetero- chromatin}

The initial characterization of RITS revealed that siRNAs are likely to guide RITS to homologous chromatin regions (Verdel et al., 2004). Two models were then postulated for RITS siRNAdependent recruitment to chromatin (Verdel et al., 2004; Verdel and Moazed, 2005) (Fig. 2). In the first model, a RITS-associated siRNA base-pairs directly with one strand of the targeted DNA double helix. In the second model, RITS' siRNA interacts with a complementary RNA bound to chromatin. RNA immunoprecipitation (RIP) experiments established that RITS and RDRC interact with centromeric RNAs in vivo, and that for both complexes their interaction with RNA requires CIr4 and Dcr1. Thus, RITS and RDRC association with centromeric RNAs is likely to occur in the close periphery of chromatin and to require siRNAs (Motamedi et al., 2004). These results have favored the second model and led to the proposal that a nascent RNA being produced at the site of heterochromatin formation serves as a platform to recruit, through a siRNA-RNA base-pairing mechanism, RITS and RDRC to chromatin (Motamedi et al., 2004) (Figures 2 and 3).

The RNA platform model has been tested in vivo. This was achieved with a recombinant strain expressing the RITS subunit Tas3 fused to $\lambda N$, a peptide that specifically binds to the RNA motif BoxB (Buhler and Moazed, 2007; Buhler et al., 2006). In parallel, the DNA sequence encoding the BoxB RNA motif was integrated at the 3' end of ura4 gene to produce a hybrid mRNA, Ura4-BoxB. In a wild type strain, ura4 is a euchromatic gene to which RITS does not bind. However, in the recombinant strain, RITS- $\lambda N$ gets recruited to ura4-BoxB gene in a transcription dependent-manner. Thus, the designed RNA-based tethering system has validated the hypothesis that RITS can associate with chromatin just by first binding to a nascent transcript. This system has also revealed that RITS tethering to ura4-BoxB gene triggers deposition of $\mathrm{H} 3 \mathrm{~K} 9 \mathrm{me}$ and Swi6 heterochromatin marks, and the transcriptional silencing of ura4-BoxB gene. Therefore, the recruitment of RITS to chromatin appears to be sufficient to initiate heterochromatin formation and TGS.

Genetic screens designed to identify new proteins acting in heterochromatin formation have unveiled a role for RNApll in siRNA-dependent heterochromatin formation. Two point mutations in Rpb2 and Rpb7 subunits of RNApll have been found to disrupt heterochromatin formation (Djupedal et al., 2005; Kato et al., 2005). Genome-wide transcriptomic analyses have indicated that the global expression profile of protein-coding genes does not significantly change in the RNApll mutants, suggesting that disruption of heterochromatin is probably not caused by an indirect effect. Furthermore, as in Rpb2 and Rpb7 point mutants strains RNApIl associates to the same extent with centromeric repeats, it is not RNApII recruitment to the site of heterochromatin formation that is perturbed in these mutants. Closer analyses of Rpb7 point mutant strains have pointed out that it is the elongation step of centromeric transcription that is impaired, which is in agreement with the RNA platform model (Djupedal et al., 2005). Interestingly, investigations on Rpb2 mutant have also indicated that RNApll itself might be directly involved in siRNA-mediated heterochromatin formation, as although heterochromatin is impaired in this mutant strain the process of pericentromeric DNA repeats transcription remains normal (Kato et al., 2005). The findings that Ago1 interacts with RNApll Carboxy-terminal domain (CTD), and that partial deletion of the CTD disrupts centromeric heterochromatin formation supports such a role of RNApII (Schramke et al., 2005).

More recently, transcription and formation of heterochromatin at pericentromeric repeats were found to be cell cycle regulated (Chen et al., 2008; Kloc et al., 2008). A temporal succession of changes has been observed. During mitosis and G1 phases, serine 10 of histone $\mathrm{H} 3$ is phosphorylated and the condensing subunit Cut3 gets recruited to pericentromeric repeats, coinciden- 
tally Swi6 association to chromatin is nearly completely lost. In S phase, just before pericentromeric RNAs accumulate, the enrichment for Cut3 drops. Ago1 and Rik1, a component of Clr4 complex (Hong et al., 2005; Horn et al., 2005; Jia et al., 2004a, Li et al., 2005) then bind pericentromeric DNA before the association of Swi6 and H3K9me marks increases again. Based on the sequential nature of these events, it has been proposed that transcription of centromeres enables the recruitment of complexes, like RITS and the CIr 4 complex, which would in turn facilitate heterochromatin formation in a cell cycle dependent fashion (Chen et al., 2008; Kloc et al., 2008; Zhang et al., 2008). Thus, a boost of transcription

\section{A siRNA-DNA base-pairing}

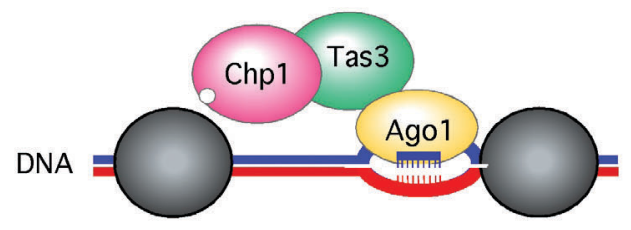

B SIRNA-RNA base-pairing
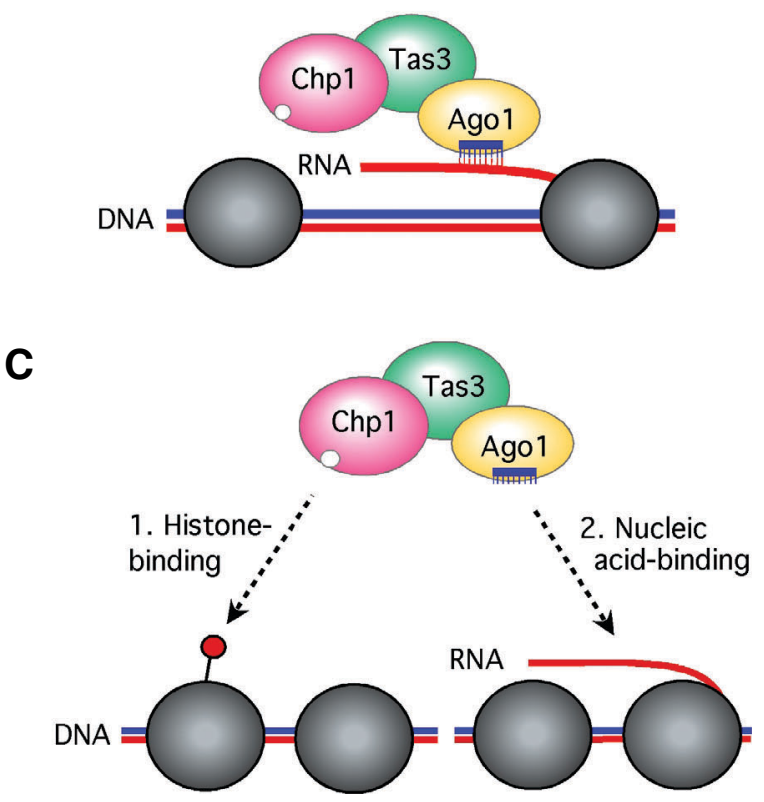

Fig. 2. Recruitment of the fission yeast RNAi effector complex RITS to chromatin. Two models have been proposed for the siRNA-driven binding of RITS to chromatin. RITS is formed by the association of three proteins Chp1, Ago1 and Tas3, with a siRNA (small blue line), bound to Ago1. The first model (A) proposes a base-pairing between a siRNA incorporated into RITS and a complementary strand of DNA. This model implies the necessity to unwind the DNA double-helix to allow interaction. In the second model (B) a RITS-associated siRNA base-pairs with a complementary nascent transcript. Several evidences strongly support the siRNA-Nascent transcript model (see text for more details). (C) In addition to the Ago1-bound siRNA, RITS possess a second chromatintargeting module, which is a chromodomain present at the $N$-terminus of Chp1 (little white circle). This chromodomain binds specifically to the heterochromatin mark H3K9me (small red lollipop shape). RITS stable binding to chromatin necessitates a close interplay between these two targeting modules. See text for further details. at each cell cycle might be an important step for the efficient epigenetic maintenance of siRNA-mediated heterochromatin formation. Further investigations shall indicate if this is indeed the case.

\section{Association of RITS with chromosomes}

RITS is so far the unique example of an Argonaute-containing complex directly acting on genomic DNA (Verdel et al., 2004). Detailed examinations of RITS recruitment to chromatin have begun to dissect the underlying mechanisms responsible for its binding to chromatin. As described above, a siRNA-nascent RNA base-pairing mechanism can play a central role in recruiting RITS to chromatin (Motamedi et al., 2004; Verdel and Moazed, 2005). However, RITS recruitment to chromatin also necessitates a chromodomain present on RITS subunit Chp1, which interacts with H3K9me2 in vitro (Partridge et al., 2007; Partridge et al., 2002) (Fig. 2). The fact that RITS turns out to be devoid of siRNAs in a $\Delta c / r 4$ strain, or when Chp1 chromodomain is inactivated, points to a strong interdependency between the Ago1-bound siRNA and the chromodomain, a situation that complicates the study of their respective role (Motamedi et al., 2004; Noma et al., 2004). Nonetheless, recent studies have highlighted important features of these two RITS chromatin-binding modules (Debeauchamp et al., 2008; Partridge et al., 2007). RITS subunit Tas3 interacts with Ago1 through a motif formed by the repetition of WG/GW amino acids (Partridge et al., 2007). Point mutations in Tas3 WG/GW motif leads to a loss of binding between Chp1Tas3 dimer and Ago1, and thereby separate the complex chromatin-binding modules. It turns out that Ago1 binding to Chp1-Tas3 is not necessary for their respective association with heterochromatin. However, when no H3K9me heterochromatin mark is present, as for establishment of heterochromatin formation, Ago1 and Chp1-Tas3 need to physically interact to bind chromatin. The observation that, under certain circumstances, RITS can trigger de novo heterochromatin formation in trans (i.e, at a distant homologous genomic site) provides a possible explanation for the difference in binding properties of Ago1 and Chp1-Tas3 in accordance with the chromatin state (Buhler et al., 2006). Experiments done with the RITS- $\lambda \mathrm{N} /$ ura4-BoxB tethering system previously described, have shown that ura4-BoxB silencing comes with the production of ura4 siRNAs. Importantly, in an eri1 deficient strain, RITS can now trigger heterochromatin formation at a second homologous ura4 locus (Buhler et al., 2006). The eri1 gene encodes a ribonuclease believed to be a negative regulator of RNAi by degrading siRNAs (lida et al., 2006). Thus, it seems that RITS has the potential to form heterochromatin in trans but that such mechanism is limited by eri1 in wild type strain. Although further investigations are required to understand the mechanism of this cis-restriction, the existence of a cellular condition under which RITS mediates heterochromatin formation in trans clearly supports the idea that a RITS-associated siRNA can be sufficient to guide RITS to chromatin. The close interplay between the Ago1-bound siRNA and the Chp1 chromodomain might be to actually stabilize RITS binding to chromatin by its anchorage to $\mathrm{H} 3 \mathrm{~K} 9 \mathrm{me}$. If this mechanism is correct, then RITS targeting to chromatin must be closely followed by Clr4 recruitment to methylate $\mathrm{H} 3 \mathrm{~K} 9$ and enable RITS to efficiently associate with chromatin. The recent finding that CIr4 interacts with RITS and the observation that RITS cell cycle association to centromeric heterochro- 
matin might be closely linked to Clr4 complex recruitment favor such mechanism (Chen et al., 2008; Zhang et al., 2008). However, further investigations are needed to fully validate this hypothetical mechanism.

\section{Association of other RNAi proteins with chromosomes}

Rdp1 and Hrr1 association with heterochromatin (Motamedi et al., 2004; Sugiyama et al., 2005) and RDRC interaction with centromeric RNAs in a Clr4- and Dcr1-dependent manner, have led to the proposal that RDRC synthesizes dsRNA at sites of siRNA-dependent heterochromatin formation (Motamedi et al., 2004). It has also been proposed that RITS serves as a priming complex to recruit RDRC onto nascent transcripts emanating from heterochromatic regions. In parallel, recent investigations suggest that Dcr1 might also act on chromatin or at its close proximity. Dcr1 interacts with both RDRC and RITS, and Dcr1RDRC interaction greatly stimulates Rdp1's RDR activity in vitro, indicating that Dcr1 interaction with RDRC might occur on chromatin to enable the local production of siRNAs during heterochromatin formation (Colmenares et al., 2007). Taken together, these results suggest that it is actually the core machinery of RNAi, formed by RITS, RDRC and Dcr1, that localizes to heterochromatin formation nucleation centers.

\section{RNA processing and heterochromatic gene silencing}

Assembly of heterochromatin at a given genomic site comes with a heritable silencing of transcription, which has been well illustrated by the silencing of reporter genes integrated into, or juxtaposed to, heterochromatic regions, a phenomenon known as position effect variegation (PEV) (Allshire and Selker, 2007). Heterochromatic transcriptional gene silencing is believed to result from a compaction of chromatin, which lowers accessibility to DNA binding complexes such as RNApll. In fission yeast, SHREC (SNF2- and Histone deacetylase- containing REpressor Complex) is a complex believed to silence transcription by diminishing RNApll occupancy in heterochromatic regions, thanks to its potential chromatin remodeling activity (Sugiyama et al., 2007) (Fig. 3). However, RNApll occupancy does not always drop with the formation of heterochromatin, and, interestingly, in such cases a robust heterochromatin silencing is still observed, suggesting that other mechanisms than chromatin compaction might contribute to heterochromatic gene silencing (Buhler et al., 2006).

Recent studies have revealed that, in parallel to the classical DNA restriction process, active degradation of RNA might be part of the mechanism that silence transcription occurring in heterochromatic regions. The two main ribonuclease activities associated with siRNA-mediated silencing, "dicing" and "slicing", seem to both contribute to heterochromatic gene silencing (Fig. 3). Fission yeast Ago1 is endowed with a slicing activity that in vitro cleaves a target RNA when its Ago1-bound siRNA perfectly basepairs with it (Buker et al., 2007; Irvine et al., 2006). Point mutations in Ago1 that destroy its slicing activity lead to defects in heterochromatic silencing at centromeres, suggesting that in vivo Ago1 slices heterochromatic RNAs and thereby contributes to transcriptional gene silencing (Buker et al., 2007; Irvine et al., 2006). Although this is likely to be the case, it should be pointed out that Ago1 slicer is also required to eliminate the passenger strand after incorporation of the duplex siRNA into RITS (Buker et al., 2007). As elimination of the passenger-strand is a step upstream of the
siRNA-based target RNA cleavage, inefficient elimination of the passenger strand could also impair heterochromatic silencing. Further experiments are therefore needed to determine the exact contribution of both slicer-dependent steps in heterochromatic gene silencing.

In parallel to RNAi, another RNA degradation process, requiring the protein Cid14, which belongs to an atypical class of polyA polymerases (like Cid12 a subunit of RDRC), and Dis3 the main exosome ribonuclease, has also been found implicated in transcriptional silencing of all major heterochromatic sites in fission yeast (Buhler and Moazed, 2007; Murakami et al., 2007; Wang et al., 2008). In a cid14 deficient strain, heterochromatic silencing at centromeres is relieved and the level of centromeric siRNAs dramatically reduces. Surprisingly, the enrichment of H3K9me and Swi6 heterochromatic marks stays unchanged. Altogether, these results indicate that an RNA processing mechanism mediated by the exosome can contribute significantly to the heterochromatic gene silencing. The fact that a large fraction of the produced centromeric siRNAs appears not necessary for deposition of heterochromatic marks further indicates that most siRNAs might not have a function in heterochromatin formation perse (Buhler et al., 2007; Colmenares et al., 2007). The majority of siRNAs might rather be end products of a heterochromatic gene silencing mechanism based on Dcr1-dependent processing of double-stranded heterochromatic RNAs (Fig. 3).

\section{RNA-directed DNA Methylation (RdDM) in plants}

Plants are the other organisms where a siRNA-mediated chromatin modification pathway, termed RNA-directed DNA methylation ( $R d D M)$, is being extensively studied. In this section, we describe the main actors, mechanisms and roles of RdDM. Beyond DNA (Cytosine 5) methylation, which does not exist in fission yeast, important similarities between the two pathways can be pointed out, supporting the idea that a body of proteins and mechanisms is conserved between fission yeast and plants siRNA-dependent chromatin modification pathways. Further details on the proteins and mechanisms acting in the RdDM pathway and on the genomic targets of this pathway have been described in several excellent reviews (for example, see Chan et al., 2005; Matzke et al., 2007; Slotkin and Martienssen, 2007).

\section{The components}

RdDM was first observed in tobacco plants infected with pathogen circular RNA molecules known as viroids. Under viroid infection, when the pathogen RNA molecules replicate, DNA of homologous genomic sequences becomes methylated (Wassenegger et al., 1994). In a subsequent investigation also conducted in tobacco, the constitutive expression of a dsRNA matching a genomic promoter sequence was shown to result in de novo DNA methylation and transcriptional silencing of the targeted promoter (Mette et al., 2000). Importantly, the observed de novo DNA methylation and silencing come with the production of siRNAs matching the promoter sequence, which provided a first indication that siRNA-dependent mechanisms are acting in RdDM (Matzke et al., 2004; Mette et al., 2000).

DNA methylation is present throughout $A$. thaliana genome but concentrates largely on dispersed repeat sequences and centromeric regions where multiple DNA repeats accumulate (Chan et 


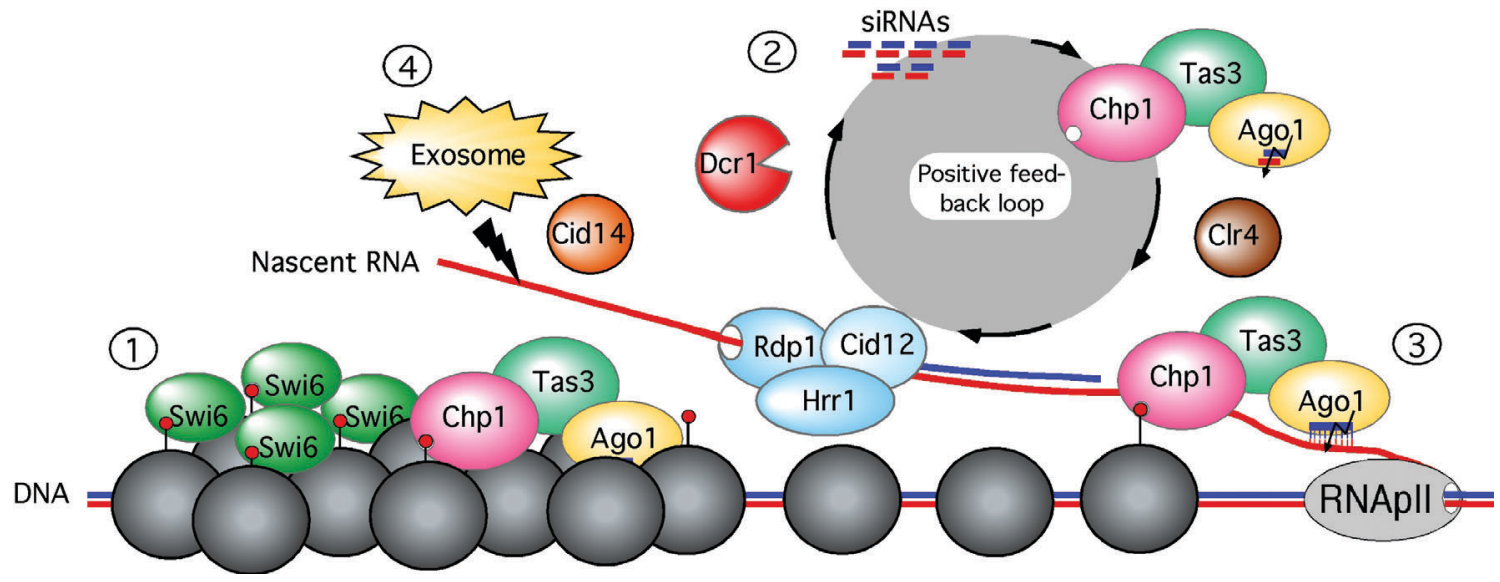

Fig. 3. Model of fission yeast siRNA-dependent heterochromatin formation and heterochromatic gene silencing. SiRNA-dependent heterochromatin formation is initiated by the production of dsRNA, which is cleaved by Dcr1 into siRNAs and incorporated onto RITS. Transcription by RNApII allows RITS to be recruited to chromatin thanks to a siRNA-Nascent RNA base-pairing. In parallel, RITS interaction with H3K9me (red lollipop) stabilizes its binding to chromatin. RITS is believed to bring RDRC to the nascent transcript to synthesize dsRNA in cis (1.e, at the site of RNAi-dependent heterochromatin formation). This dsRNA synthesis would initiate a local positive feedback loop between the production of siRNAs and the modification of chromatin, which encompasses methylation of histone $\mathrm{H} 3$ lysine 9 (H3K9me). Four possible mechanisms of heterochromatic transcriptional gene silencing are highlighted. Heterochromatin formation is thought to impose a chromatin remodeling that restricts access to DNA to RNAp/l (1). More recently, the two main enzymatic activities of the siRNA pathways, "dicing" (2), catalyzed by Dcr1, and "slicing" (3), catalyzed by Ago1 (illustrated by a black zig-zag arrow) have been proposed to degrade transcripts emanating from heterochromatin. Finally, an exosome-and Cid14-dependent RNA degradation (black thick lane shaped as a lightening) can also degrade heterochromatic RNAs (4). Note that Ago 1 slicing is also required for elimination of the passenger strand, a step upstream of the siRNA-directed cleavage of the nascent transcript.

al., 2005; Zhang et al., 2006; Zilberman et al., 2007). In A. thaliana cytosine methylation can be symmetrical when it occurs on $C G$ and $\mathrm{CNG}$ ( $\mathrm{N}$ denotes any nucleotide) or asymmetrical when it takes place on $\mathrm{CHH}$ (H denotes A, T, or C) (Chan et al., 2005). Maintenance of CG methylation is carried out by MET1, which is the plant counterpart of the mammalian Dnmt1. In parallel, most $\mathrm{CNG}$ and $\mathrm{CHH}$ methylations are maintained by DRM2, which is homologous to the Dnmt3 type methyltransferases in mammals, and by $\mathrm{CMT3}$, a plant specific DNA methyltransferase. On the contrary, de novo methylation in all nucleotide contexts (CG, CNG and $\mathrm{CHH}$ ) is catalyzed mostly by only one DNA methyltransferase, DRM2.

Forward and reverse genetic screens have uncovered major components of the RdDM pathway in A. thaliana (Baulcombe, 2004; Lippman and Martienssen, 2004; Matzke et al., 2004) (Fig. $4 \mathrm{~A})$. Among the identified proteins figure not surprisingly, the DNA methyltransferase DRM2, but also an Argonaute protein, AGO4, a dicer protein, DCL3, a RNA-directed RNA polymerase, RDR2, a histone deacetylase, HDA6, a histone methyltransferase SUVH4/ KYP, which is homologous to fission yeast Clr4, a member of the ATP-dependent chromatin remodeling superfamily, DRD1, and a plant specific and putative DNA-directed RNA polymerase, PollV. According to the identity of these proteins, it turns out that fission yeast and plant siRNA-directed chromatin modification pathways have in common a wide set of RNAi proteins, chromatin-modifying proteins and their associated enzymatic activities (Fig. 4A). A. thaliana possesses 10 predicted Argonaute genes. Not surprisingly, a partial redundancy between Argonaute proteins has been observed in RdDM. Indeed, AGO6 was found to act in parallel to, or overlap with, AGO4 to guide DNA methylation and transcriptional gene silencing (Zheng et al., 2007). As more than half of $A$. thaliana Argonaute proteins have not been studied in detail, it is quite possible that more AGO proteins with a role in RdDM will be identified.

The RNA polymerase IV, PollV, exists in two forms, PollVa and PollVb, which have apparent distinct functions in RdDM. PollVa seems involved in generating siRNAs whereas PollVb would act more downstream at the DNA methylation step (El-Shami et al., 2007; Henderson and Jacobsen, 2007; Li et al., 2006; Pontes et al., 2006; Pontier et al., 2005). Conversely to PollVb, PollVa does not possess an extended CTD repeat (El-Shami et al., 2007). Interestingly, like fission yeast Ago1, which interacts with RNApll through its CTD, AGO4 associates with the CTD of PollVb (EIShami et al., 2007). PollVb interaction with AGO4 is essential for RdDM, suggesting that PollVb and AGO4 tightly cooperates in siRNA-directed de novo DNA methylation (El-Shami et al., 2007).

\section{The pathway}

The sequence of events starting from the activation of the pathway and leading to DNA methylation has been partially revealed by cytological studies investigating on the subcellular location of RdDM components in different genetic backgrounds (Li et al., 2006; Pontes et al., 2006). It has been proposed that RDR2 and/or PollVa recognize aberrant RNAs, and convert them into dsRNAs that are then digested by DCL3 to produce siRNAs, which are loaded onto AGO4 proteins. An AGO4 protein bound to a siRNA may form a complex with PollVb and DRM2 to guide DNA methylation and $\mathrm{H} 3 \mathrm{~K} 9$ methylation at the target genomic region (Henderson and Jacobsen, 2007) (Fig. 4A). Part of the RdDM actors have been found in nuclear processing centers that colocalize partially with the nucleolus (Li et al., 2008; Li et al., 2006; Pontes et al., 2006). Other genetics investigations have suggested that DRD1 acts together with AGO4 to enable DRM2 to access the target DNA to carry out de novo DNA methylation 
(Huettel et al., 2006; Huettel et al., 2007).

\section{Mechanisms of siRNA-directed target recognition}

Currently, it is not known whether AGO4-associated siRNA base-pairs with a nascent transcript, like in fission yeast, or directly with DNA. Early experiments analyzing the pattern of de novo DNA methylation have indicated that it is mainly restricted to the region of homology between the RNA trigger and the genomic target, which is more in favor of a RNA-DNA interaction (Pelissier and Wassenegger, 2000). On the opposite, more recent experiments have revealed that AGO4 possesses a slicer activity and that AGO4 slicing is required for a subset of RdDM targets, supporting the idea that, like in fission yeast, plant siRNA-driven chromatin modifications might go through a siRNA-nascent RNA type of interaction (Qi et al., 2006). The fact that not all genomic targets of RdDM are sensitive to AGO4 slicing activity might reflect the existence of both siRNA-RNA and siRNA-DNA basepairing mechanisms. Alternatively, at some of the genomic loci other Argonaute proteins may act in parallel to AGO4. Further investigations are therefore needed to uncover the molecular mechanism(s) by which a siRNA guides de novo methylation in plants.

\section{Regulation of centromeres, repetitive elements and protein- coding genes}

Centromeres in plants contain thousands tandem copies of short satellite repeats as well as many retrotransposons. In $A$. thaliana, these repeated elements are transcribed, and their corresponding RNAs localize in the nucleus where they are processed in a RNAi-dependent fashion to give rise to siRNAs (May et al., 2005). A direct implication of RdDM at centromeric repeats is also supported by the facts that centromeric siRNAs are lost in $d c / 3$ and $r d r 2$ mutants, while centromeric RNAs accumulate concomitantly. Moreover, an important fraction of AGO4-bound siRNAs match pericentromeric regions (Qi et al., 2006). The heterochromatin mark $\mathrm{H} 3 \mathrm{~K} 9 \mathrm{me} 2$ present in these regions is, however, not lost in $d c / 3$ and $r d r 2$ mutants, indicating that one or more mechanisms contribute to establish and/or maintain heterochromatin at centromeres independently of RdDM. Thus, this situation might be reminiscent of fission yeast siRNA-dependent heterochromatin formation at the mating-type locus where a redundant pathway maintains heterochromatin formation in a RNAi-independent manner (Hall et al., 2002).

The high-throughput sequencing of siRNAs associated with AGO4 has revealed that a large fraction matches transposons and other repetitive elements catalogued in $A$. thaliana (Qi et al., 2006), pointing out that most transposons might be targeted by RdDM. However, for most transposons, their transcription silencing and DNA methylation do not require RdDM components and rather depend on the DNA methyltransferase MET1 and the chromatin remodeling protein DDM1 (Slotkin and Martienssen, 2007). The $A$. thaliana FWA gene is a well-studied example of a developmental gene targeted and regulated by DNA methylation. FWA protein is a homeodomain-containing transcription factor
A RdDM

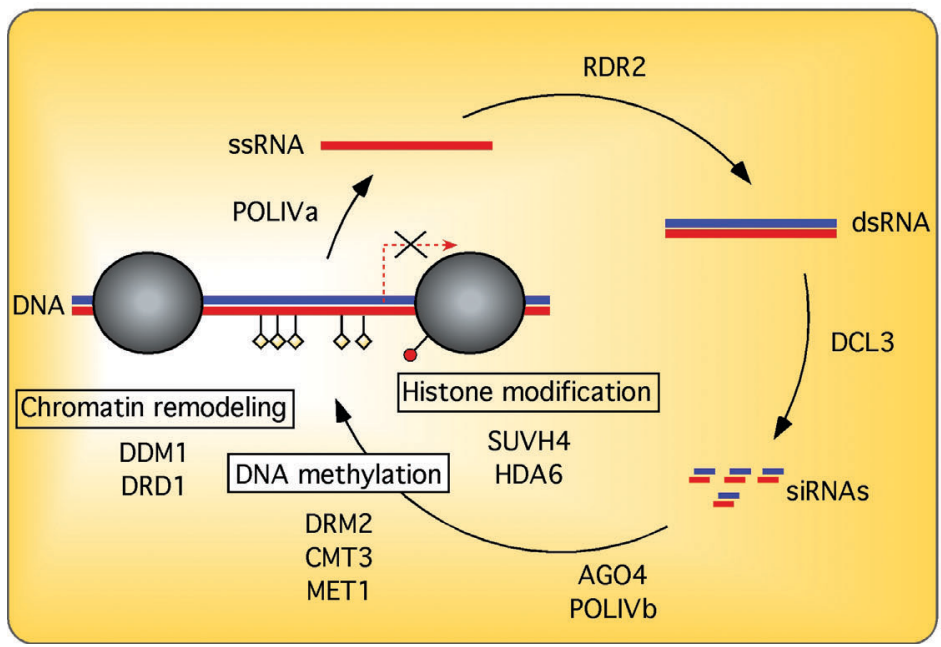

B

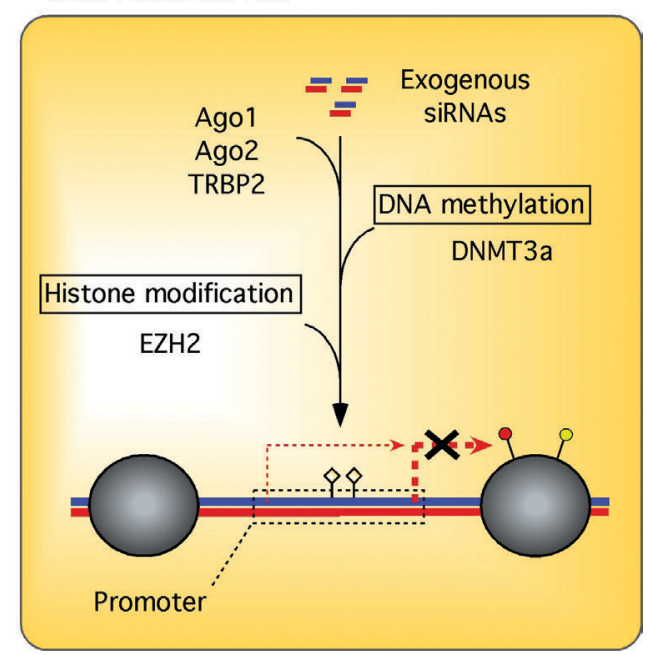

Fig. 4. Plant RNA-directed DNA methylation and mammalian siRNA-directed TGS pathways. (A) A proposed model for RdDM in A.thaliana. One form of RNA polymerase IV, POLIVa, gets recruited to a target genomic site (for example a transposon or DNA tandem repeats), through an unknown mechanism. Once recruited, POLIVa synthesizes a single-stranded RNA (ssRNA). RDR2 uses this ssRNA as a template to synthesize a dsRNA that is then processed by DCL3 into siRNAs that bind AGO4 proteins. SiRNAs-bound to AGO4 proteins together with POLIVb, the second form of POLIV that interacts with AGO4, initiate in a sequence-specific manner de novo DNA methylation, histone methylation as well as a probable ATP-dependent chromatin remodeling. Given that at some RdDM targeted loci, siRNAs are not detected in absence of the de novo cytosine methyltransferase DRM2, it is possible that a positive feedback loop (like in fission yeast) is required for efficient siRNA-dependent de novo methylation and gene silencing. (B) Model for the siRNA-directed TGS observed in mammalian cell lines. Transfection of synthetic siRNAs or production of exogenous siRNAs (from vectors that produce small RNA hairpins that are then processed into siRNAs by a Dicer proteins) silence endogenous genes when the siRNAs target their promoter. Presumably, a low level of RNApll transcription in the targeted promoter provides a RNA template onto which the siRNA-Ago complexes bind. In addition to Ago1, Ago2 and their common partner TRBP2, the DNA methyltransferase (homologous to the A. thalina DRM2) and the Polycomb group histone methyltransferase EZH2 would also be recruited to the targeted promoter. The siRNA-directed gene silencing comes with de novo DNA methylation and/or repressive histone H3 methylation on lysine 9 and 27. Yellow diamond flags represent cytosine methylation. 
which expression is subjected to imprinting as it is solely expressed from its maternal gene, in the central cell and the endosperm tissue. A tandem repeat present in FWA promoter appears to attract DNA methylation and to be necessary for its imprinting. Introduction in the genome of extra copies of FWA by Agrobacterium tumefaciens transformation has been found to trigger their DNA methylation presumably through the RdDM pathway as DCL3, AGO4, RDR2 and PollV are all required for methylation of FWA extracopies (Chan et al., 2004). Intriguingly, efficient de novo methylation of FWA transgenic copies requires the endogenous FWA gene to be methylated (Chan et al., 2006). The level of FWA siRNAs appears to be unchanged whether the FWA gene is or is not methylated, indicating that the siRNAs are not sufficient to establish FWA DNA methylation. Similarly to fission yeast siRNA-mediated heterochromatin formation pathway, this might indicate that a co-occurrence of chromatin modification and siRNA production is needed for efficient siRNAdirected DNA methylation. A case of RdDM potentially triggered by antisense transcription has been recently reported at the FLC (Flowering Locus C) gene. FLC is a key negative regulator of flowering gene that belongs to the MADS box gene family of transcription factors with critical roles in the progression of multiple cellular differentiation processes. The FLC gene expression is maintained at a low level in early flowering $A$. thaliana by Polycomb group silencing proteins. A transposon present in an intron of FLC gene is believed to nucleate formation of silent chromatin by attracting DNA and H3K9 methylation (Liu et al., 2004). More recently, siRNAs matching the 3' end of FLC gene have been detected and their accumulation requires DCL3, RDR2 and PollVa (Swiezwesky et al., 2007). Interestingly, the production of siRNAs does not seem to depend on the nearby transposon located in the 5' part of the gene, but rather on antisense transcription of FLC 3' UTR. The origin of this antisense transcription is not yet clear but this transcription might represent a new mean to trigger RdDM, which works independently of a repeated DNA sequence.

\section{SiRNA-based chromatin modifications in animals}

\section{SiRNA-directed transcriptional gene silencing (TGS)}

Synthetic siRNAs delivered into mammalian cell lines by transfection are commonly used to silence the expression of a given protein by cytoplasmic RNAi. However, under certain conditions that are not yet completely clear, some siRNAs can act directly on chromosomes and trigger TGS. The first example of a siRNAdirected TGS came from siRNAs targeting a recombinant DNA construction integrated in the genome and formed by the fusion of Elongation Factor 1 alpha (EF1a) promoter to the Green Fluorescence Protein (GFP) coding sequence (Morris et al., 2004). The observed gene silencing correlates with a targeted deposition of cytosine methylation at the EF1a promoter and of H3K9me2. Run-ON experiments have shown that the silencing occurs at the transcriptional level. Noticeably, when a siRNA matching the GFP coding sequence is used, neither silencing nor appearance of repressive chromatin modifications is observed, indicating that siRNAs must target the promoter to trigger TGS, which is reminiscent of plant RdDM. TGS triggered by transfection of synthetic siRNAs has since been observed at several endogenous genes (Janowski et al., 2006; Kim et al., 2006; Ting et al., 2005;
Weinberg et al., 2006; Zhang et al., 2005) and similar results have also been reported with vectors that constitutively express shorthairpin RNAs matching a given promoter sequence (Castanotto et al., 2005; Kim et al., 2007; Pulukuri and Rao, 2007).

In a follow-up study using the same "EF1a-GFP" system, it was found through the use of $\alpha$-amanatin, a molecule that inhibits specifically RNApll, that RNApll transcription is likely to be required for TGS as the deposition of the H3K9me2 mark at the targeted site depends on RNApll activity (Weinberg et al., 2006). In parallel, the DNA methyltransferase DNMT3a, which mediates de novo DNA methylation and is homologous to A.thaliana DRM2, is recruited to the EF1a promoter in a siRNA-dependent fashion. It has been proposed that siRNAs base-pair with a nascent RNA emanating from the targeted promoter. This model is based on the recent finding that EF1a gene produces a low level of EF1a specific mRNAs with an extended 5' UTR that covers part of EF1a promoter. A targeted blockade of this extended mRNA inhibits siRNA-directed TGS against EF1a, indicating that production of a nascent transcript in the targeted promoter is likely to be necessary for siRNA-directed TGS (Han et al., 2007).

By a candidate approach, it has been found that Ago1 associates with both human immunodeficiency virus-1 coreceptor CCR5 and tumor suppressor RASSF1A promoters, only when they are subjected to synthetic siRNA-directed silencing (Kim et al., 2006) (Fig. 4B). Ago1 is likely to be necessary for siRNAdirected TGS as Ago1 knockdown results in the loss of H3K9me2 enrichment that comes with the silencing of the targeted promoters. Additionally, Ago2 and TRBP2, which binds both Ago1 and Ago2, are recruited to siRNA-targeted promoters (Janowski et al., 2006; Kim et al., 2006). The post-translational mark H3K27me3, which like H3K9me2 associates with silent chromatin imposed by Polycomb Group (PcG) proteins, is also present at the silenced promoter, suggesting that PcG proteins might be implicated in siRNA-directed TGS. The Polycomb protein and histone methyltransferase EZH2, which catalyses the H3K27me3 mark, also associates with the silenced promoter, further supporting a connection between siRNA-directed TGS and PcG proteins. Interestingly, Ago1 colocalizes with EZH2 and H3K27me3 onto the MYT gene, a natural PcG target gene, suggesting that Ago1 bound to endogenous siRNAs might participate in natural PcGdependent silencing. But, although these data indicate that a synthetic siRNA can under certain circumstances trigger siRNAdirected TGS, more investigations are needed especially to establish if a natural siRNA-dependent pathway imposes a regulated TGS in animals, like in fission yeast and plants.

\section{Centromeres and transposable elements}

As in fission yeast, and possibly in plants, siRNA-mediated heterochromatin formation at centromeres might occur in vertebrates. Experiments based on permeabilization and RNAse treatments of mammalian cell lines have found that HP1- $\alpha$ localization to centromeres depends on a RNA (Maison et al., 2002). Mouse pericentromeric repeats are transcribed and their transcription might be regulated during cell cycle, like in fission yeast (Lu and Gilbert, 2007). This transcription regulation is likely to be important for centromere function as forced overexpression of centromeric RNAs leeds to defects in centromere architecture, chromosome segregation and sister-chromatid cohesion (BouzinbaSegard et al., 2006). 
Several investigations have examined the possible implication of a siRNA-dependent pathway in the formation of heterochromatin and transcriptional silencing at centromeres. Inactivation of Dicer, by knockout or knockdown, has suggested that siRNAmediated heterochromatin formation might take place in vertebrates. In chicken cell lines containing a human chromosome 21 , the inducible loss of Dicer expression has been correlated to loss of heterochromatin, accumulation of $\alpha$-satellite RNAs and chromosome defects (Fukagawa et al., 2004). Similarly, in mouse embryonic stem cells conditional knockouts of Dicer lead to an accumulation of RNAs from minor and major satellite centromeric repeats, and a more or less reduction of H3K9 di-and tri-methylated levels at these repeats (Kanellopoulou et al., 2005; Murchison et al., 2005). In flies, increased defects in the assembly of functional centromeres are associated with mutations in Ago2 and dFMR1 (Deshpande et al., 2005; Deshpande et al., 2006), a protein that interacts with Ago2 (Ishizuka et al., 2002). Nonetheless, like in plants, no direct connection has been made so far between a siRNA-dependent pathway and formation of centromeric heterochromatin.

In parallel, a role for siRNAs in the regulation of transposable elements is becoming evident. In mouse embryos, knockdown of Dicer by injection of dsRNA correlates with an accumulation of $L 1$ transposon RNAs, suggesting that they might be regulated by a siRNA-dependent process (Svoboda et al., 2004). Similar results have been obtained from mouse investigations done with Dicer/- ES cells (Kanellopoulou et al., 2005). Retrotransposition assays conducted in cell lines have further indicated that partial inactivation of Dicer by knockdown leads to an increase in L1 retransposition (Yang and Kazazian, 2006). Recently, highthroughput sequencing of small RNAs has revealed that a large fraction of endogenous siRNAs in flies and mammals match transposons and other repetitive sequences (Czech et al., 2008; Ghildiyal et al., 2008; Okamura et al., 2008; Tam et al., 2008; Watanabe et al., 2008). However, it remains to be determined if these transposon-derived siRNAs can mediate siRNA-dependent chromatin modifications. The facts that mammalian $\mathrm{L} 1$ retrotransposon transcripts are confined to the nucleus (Swergold, 1990) and that DNA methylation suppresses L1 transposition (Yu et al., 2001) might be indications of a siRNA-directed epigenetic regulation of transposon mobility occurring in animals, like in plants.

\section{Summary and perspective}

Ongoing investigations on endogenous siRNA-mediated chromatin modification pathways are dissecting their underlying mode of action and are beginning to reveal their function. A common body of RNAi- and chromatin-linked proteins appears conserved between fission yeast and plants. In these organisms, siRNAs can guide Argonaute proteins and other proteins to chromatin. Once on chromatin, the proteins directly or indirectly induce a local modification of chromatin structure and function. In fission yeast, transcription of heterochromatic DNA by RNApll produces nascent transcripts, which are believed to serve as RNA platforms to recruit RNAi complexes such as RITS and RDRC. The putative RNApIV might exert the same function in $A$. thaliana. The additional physical connections uncovered between Argonaute proteins and RNApII or RNApIV further support a central implication of RNA polymerases in siRNA-mediated chromatin modifications. In parallel, the recent deep sequencing analyses of small RNAs are pointing to the existence of endogenous siRNA-mediated silencing pathways in flies and mammals. Interestingly, other investigations suggest that, like in fission yeast and $A$. thaliana, siRNA-mediated silencing can involve chromatin modifications in mammals. Furthermore, preliminary experiments indicate that the central role of transcription in siRNA-mediated chromatin modifications may also be conserved in mammals.

It should be pointed out that although common proteins, mechanisms and functions appear to be shared between siRNAmediated epigenetic silencing pathways certain aspects of these pathways turn out to be species specific. SiRNA-directed DNA methylation observed in plants and mammalian cells does not occur in fission yeast, which lacks genes encoding a functional DNA methyltransferase. In fission yeast, a positive-feedback loop couples siRNA production to chromatin modifications and involves an RNA-directed RNA polymerase. The same interdependency might be true for RNA-directed DNA methylation in plants. In flies and vertebrates, if this interdependency is conserved, it must involve other mechanisms, as RNAi-related RDR polymerases are not expressed.

SiRNA-mediated epigenetic silencing pathways might be actually acting in a large range of eukaryotes. For example, genetic studies in $C$. elegans have revealed the implication of Dicer, RDR and Argonaute homologues in transcriptional silencing linked to the integration of ectopic DNA in the worm genome (Grishok et al., 2005; Kim et al., 2005; Robert et al., 2005). A process occurring in Neurospora crassa and known as meiotic silencing by unpaired DNA (MSUD) might also involve a siRNA-dependent epigenetic silencing pathway (Shiu et al., 2006). In addition, in Tetrahymena termophila, a RNAi-related pathway requiring a Dicer protein is involved in a massive and programmed elimination of genomic DNA (Yao and Chao, 2005). Intriguingly, an Argonaute protein from the Piwi clade is also required for this programmed genomic rearrangement (Malone et al., 2005). Thus, it is not yet clear whether this RNAi-based DNA elimination is mediated by siRNAs and/or piRNAs. Similarly, several investigations in flies have reported a link between RNAi and heterochromatin formation (Pal-Bhadra et al., 2004; Riddle et al., 2008). However, it remains to be determined whether the chromatin silencing is mediated by siRNAs, as Piwi proteins are required for this silencing process.

Finally, a common aspect between all known or potential siRNA-mediated epigenetic silencing pathways is the repetitive nature of their DNA targets. These pathways might have evolved from the struggle to maintain a viable level of genomic stability by minimizing genomic rearrangements associated with repetitive DNA. Interestingly, in certain cases DNA repeats appear to have acquired an important biological function. For example, in fission yeast pericentromeric repeats are essential for proper chromosome segregation by initiating siRNA-dependent heterochromatin formation. In plants, some repeats can impact on the development of the organism by nucleating siRNA-mediated assembly of silent chromatin over surrounding protein-coding genes. These latter features may actually be conserved in a wide range of eukaryotes. Ongoing and future investigations will certainly reveal more exciting insights in the extent of mechanisms and functions shared by siRNA-mediated epigenetic silencing pathways across the eukaryotic kingdom. 
Note: Since the submission of this review, several reports have described the purification and characterization of PollVa and PollVb; a recent review by Matzke et al. summarizes these last findings (Matzke et al. 2009). Moreover, PollVa and PollVb polymerases have been renamed Pol IV and Pol V, respectively.

\section{Acknowledgments}

We apologize to researchers whose work could not be acknowledged due to space constraints. We thank E.C. Ibrahim and R. Pillai for their critical readings, and $D$. Moazed for his constant support and encouragement. A. Verdel belongs to the staff of the Centre National de la Recherche Scientifique (CNRS). A. Vavasseur is supported by a doctoral fellowship from the French ministry of research. Research in our laboratory is supported by the Institut National de la Santé et de la Recherche Médicale (INSERM), the international Human Frontier Science Program Organization (HFSPO), the Association pour la Recherche contre le Cancer (ARC) and the European Research Council (ERC) FP7.

\section{References}

ALLSHIRE, R.C. and SELKER, E., U. (2007). Fungal models for epigenetic research: Schizosaccharomyces pombe and neurospora crassa. Cold Spring harbor Laboratory Press.

ARAVIN, A.A., SACHIDANANDAM, R., GIRARD, A., FEJES-TOTH, K. and HANNON, G.J. (2007). Developmentally regulated pirna clusters implicate mili in transposon control. Science 316: 744-747.

BARTEL, D.P. (2004). Micrornas: Genomics, biogenesis, mechanism, and function. Cell 116: 281-297.

BAULCOMBE, D. (2004). Rna silencing in plants. Nature 431: 356-363.

BOUZINBA-SEGARD, H., GUAIS, A. and FRANCASTEL, C. (2006). Accumulation of small murine minor satellite transcripts leads to impaired centromeric architecture and function. Proc Natl Acad Sci U S A 103: 8709-8714.

BUHLER, M., HAAS, W., GYGI, S.P. and MOAZED, D. (2007). Rnai-dependent and -independent rna turnover mechanisms contribute to heterochromatic gene silencing. Cell 129: 707-21.

BUHLER, M. and MOAZED, D. (2007). Transcription and rnai in heterochromatic gene silencing. Nat Struct Mol Biol 14: 1041-1048.

BUHLER, M., VERDEL, A. and MOAZED, D. (2006). Tethering rits to a nascent transcript initiates rnai- and heterochromatin-dependent gene silencing. Cell 125: 873-886.

BUKER, S.M., IIDA, T., BUHLER, M., VILLEN, J., GYGI, S.P., NAKAYAMA, J. and MOAZED, D. (2007). Two different argonaute complexes are required for sirna generation and heterochromatin assembly in fission yeast. Nat Struct Mol Biol 14: 200-207.

CAM, H.P., SUGIYAMA, T., CHEN, E.S., CHEN, X., FITZGERALD, P.C. and GREWAL, S.I. (2005). Comprehensive analysis of heterochromatin- and rnaimediated epigenetic control of the fission yeast genome. Nat Genet 37: 809819.

CASTANOTTO, D., TOMMASI, S., LI, M., LI, H., YANOW, S., PFEIFER, G.P. and ROSSI, J.J. (2005). Short hairpin rna-directed cytosine (cpg) methylation of the rassf1a gene promoter in hela cells. Mol Ther 12: 179-183.

CHAN, S.W., HENDERSON, I.R. and JACOBSEN, S.E. (2005). Gardening the genome: DNA methylation in arabidopsis thaliana. Nat Rev Genet 6: 351-360.

CHAN, S.W., ZHANG, X., BERNATAVICHUTE, Y.V. and JACOBSEN, S.E. (2006) Two-step recruitment of rna-directed DNA methylation to tandem repeats. PLOS Biol 4: e363.

CHAN, S.W., ZILBERMAN, D., XIE, Z., JOHANSEN, L.K., CARRINGTON, J.C. and JACOBSEN, S.E. (2004). Rna silencing genes control de novo DNA methylation. Science 303: 1336.

CHEN, E.S., ZHANG, K., NICOLAS, E., CAM, H.P., ZOFALL, M. and GREWAL, S.I. (2008). Cell cycle control of centromeric repeat transcription and heterochromatin assembly. Nature 451: 734-737.

COLMENARES, S.U., BUKER, S.M., BUHLER, M., DLAKIC, M. and MOAZED, D. (2007). Coupling of double-stranded rna synthesis and sirna generation in fission yeast rnai. Mol Cell 27: 449-461.

CZECH, B., MALONE, C.D., ZHOU, R., STARK, A., SCHLINGEHEYDE, C., DUS, M., PERRIMON, N., KELLIS, M., WOHLSCHLEGEL, J.A., SACHIDANANDAM, R. et al. (2008). An endogenous small interfering rna pathway in drosophila. Nature 453: 798-802.

DE FOUGEROLLES, A., VORNLOCHER, H.P., MARAGANORE, J. and LIEBERMAN, J. (2007). Interfering with disease: A progress report on sirnabased therapeutics. Nat Rev Drug Discov 6: 443-453.

DEBEAUCHAMP, J.L., MOSES, A., NOFFSINGER, V.J., ULRICH, D.L., JOB, G., KOSINSKI, A.M. and PARTRIDGE, J.F. (2008). Chp1-tas3 interaction is required to recruit rits to fission yeast centromeres and for maintenance of centromeric heterochromatin. Mol Cell Biol 28: 2154-2166.

DESHPANDE, G., CALHOUN, G. and SCHEDL, P. (2005). Drosophila argonaute2 is required early in embryogenesis for the assembly of centric/centromeric heterochromatin, nuclear division, nuclear migration, and germ-cell formation. Genes Dev 19: 1680-1685.

DESHPANDE, G., CALHOUN, G. and SCHEDL, P. (2006). The drosophila fragile $\mathrm{x}$ protein dfmr1 is required during early embryogenesis for pole cell formation and rapid nuclear division cycles. Genetics 174: 1287-1298.

DJUPEDAL, I., PORTOSO, M., SPAHR, H., BONILLA, C., GUSTAFSSON, C.M., ALLSHIRE, R.C. and EKWALL, K. (2005). Rna pol ii subunit rpb7 promotes centromeric transcription and rnai-directed chromatin silencing. Genes Dev 19: 2301-2306.

EL-SHAMI, M., PONTIER, D., LAHMY, S., BRAUN, L., PICART, C., VEGA, D., HAKIMI, M.A., JACOBSEN, S.E., COOKE, R. and LAGRANGE, T. (2007). Reiterated $\mathrm{wg} / \mathrm{gw}$ motifs form functionally and evolutionarily conserved argonaute-binding platforms in rnai-related components. Genes Dev 21: 25392544.

FIRE, A., XU, S., MONTGOMERY, M.K., KOSTAS, S.A., DRIVER, S.E. and MELLO, C.C. (1998). Potent and specific genetic interference by doublestranded ma in caenorhabditis elegans. Nature 391: 806-811.

FUKAGAWA, T., NOGAMI, M., YOSHIKAWA, M., IKENO, M., OKAZAKI, T., TAKAMI, Y., NAKAYAMA, T. and OSHIMURA, M. (2004). Dicer is essential for formation of the heterochromatin structure in vertebrate cells. Nat Cell Biol 6: 784-791.

GHILDIYAL, M., SEITZ, H., HORWICH, M.D., LI, C., DU, T., LEE, S., XU, J., KITTLER, E.L., ZAPP, M.L., WENG, Z. etal. (2008). Endogenous sirnas derived from transposons and mrnas in drosophila somatic cells. Science 320: 10771081.

GREWAL, S.I. and JIA, S. (2007). Heterochromatin revisited. Nat Rev Genet 8: 3546.

GREWAL, S.I. and MOAZED, D. (2003). Heterochromatin and epigenetic control of gene expression. Science 301: 798-802.

GREWAL, S.I. and RICE, J.C. (2004). Regulation of heterochromatin by histone methylation and small rnas. Curr Opin Cell Biol 16: 230-238.

GRISHOK, A., SINSKEY, J.L. and SHARP, P.A. (2005). Transcriptional silencing of a transgene by rnai in the soma of c. Elegans. Genes Dev 19: 683-696.

HALL, I.M., SHANKARANARAYANA, G.D., NOMA, K., AYOUB, N., COHEN, A and GREWAL, S.I. (2002). Establishment and maintenance of a heterochromatin domain. Science 297: 2232-2237.

HAN, J., KIM, D. and MORRIS, K.V. (2007). Promoter-associated rna is required for rna-directed transcriptional gene silencing in human cells. Proc Natl Acad Sci U S A 104: 12422-12427.

HANSEN, K.R., IBARRA, P.T. and THON, G. (2006). Evolutionary-conserved telomere-linked helicase genes of fission yeast are repressed by silencing factors, rnai components and the telomere-binding protein taz1. Nucleic Acids Res 34: 78-88.

HENDERSON, I.R. and JACOBSEN, S.E. (2007). Epigenetic inheritance in plants. Nature 447: 418-424.

HONG, E.J., VILLEN, J., GERACE, E.L., GYGI, S.P. and MOAZED, D. (2005). A cullin $\mathrm{e} 3$ ubiquitin ligase complex associates with rik1 and the clr4 histone h3$\mathrm{k} 9$ methyltransferase and is required for rnai-mediated heterochromatin formation. RNA Biol 2: 106-111.

HORN, P.J., BASTIE, J.N. and PETERSON, C.L. (2005). A rik1-associated, cullindependent e3 ubiquitin ligase is essential for heterochromatin formation. Genes Dev 19: 1705-1714. 
HUETTEL, B., KANNO, T., DAXINGER, L., AUFSATZ, W., MATZKE, A.J. and MATZKE, M. (2006). Endogenous targets of rna-directed DNA methylation and pol iv in arabidopsis. Embo J 25: 2828-2836.

HUETTEL, B., KANNO, T., DAXINGER, L., BUCHER, E., VAN DER WINDEN, J., MATZKE, A.J. and MATZKE, M. (2007). Rna-directed DNA methylation mediated by drd1 and pol ivb: A versatile pathway for transcriptional gene silencing in plants. Biochim Biophys Acta 1769: 358-374.

IIDA, T., KAWAGUCHI, R. and NAKAYAMA, J. (2006). Conserved ribonuclease, eri1, negatively regulates heterochromatin assembly in fission yeast. Curr Biol 16: 1459-1464

IRVINE, D.V., ZARATIEGUI, M., TOLIA, N.H., GOTO, D.B., CHITWOOD, D.H., VAUGHN, M.W., JOSHUA-TOR, L. and MARTIENSSEN, R.A. (2006). Argonaute slicing is required for heterochromatic silencing and spreading. Science 313: 1134-1137.

ISHIZUKA, A., SIOMI, M.C. and SIOMI, H. (2002). A drosophila fragile x protein interacts with components of rnai and ribosomal proteins. Genes Dev 16: 2497 508.

JANOWSKI, B.A., HUFFMAN, K.E., SCHWARTZ, J.C., RAM, R., NORDSELL, R., SHAMES, D.S., MINNA, J.D. and COREY, D.R. (2006). Involvement of ago1 and ago2 in mammalian transcriptional silencing. Nat Struct Mol Biol 13: 787792.

JIA, S., NOMA, K. and GREWAL, S.I. (2004a). Rnai-independent heterochromatin nucleation by the stress-activated atf/creb family proteins. Science 304: 1971 1976.

JIA, S., YAMADA, T. and GREWAL, S.I. (2004b). Heterochromatin regulates cell type-specific long-range chromatin interactions essential for directed recombination. Cell 119: 469-480.

KANELLOPOULOU, C., MULJO, S.A., KUNG, A.L., GANESAN, S., DRAPKIN, R., JENUWEIN, T., LIVINGSTON, D.M. and RAJEWSKY, K. (2005). Dicer-deficient mouse embryonic stem cells are defective in differentiation and centromeric silencing. Genes Dev 19: 489-501.

$\mathrm{KANOH}$, J., SADAIE, M., URANO, T. and ISHIKAWA, F. (2005). Telomere binding protein taz1 establishes swi6 heterochromatin independently of rnai at telomeres. Curr Biol 15: 1808-1819.

KATO, H., GOTO, D.B., MARTIENSSEN, R.A., URANO, T., FURUKAWA, K. and MURAKAMI, Y. (2005). Rna polymerase ii is required for rnai-dependent heterochromatin assembly. Science 309: 467-469.

KIM, D.H., VILLENEUVE, L.M., MORRIS, K.V. and ROSSI, J.J. (2006). Argonaute1 directs sirna-mediated transcriptional gene silencing in human cells. Nat Struct Mol Biol 13: 793-797.

KIM, H.S., CHOI, E.S., SHIN, J.A., JANG, Y.K. and PARK, S.D. (2004). Regulation of swi6/hp1-dependent heterochromatin assembly by cooperation of components of the mitogen-activated protein kinase pathway and a histone deacetylase clr6. J Biol Chem 279: 42850-42859.

KIM, J.K., GABEL, H.W., KAMATH, R.S., TEWARI, M., PASQUINELLI, A., RUAL, J.F., KENNEDY, S., DYBBS, M., BERTIN, N., KAPLAN, J.M. et al. (2005). Functional genomic analysis of rna interference in c. Elegans. Science 308 : 1164-1167.

KIM, J.W., ZHANG, Y.H., ZERN, M.A., ROSSI, J.J. and WU, J. (2007). Short hairpin rna causes the methylation of transforming growth factor-beta receptor ii promoter and silencing of the target gene in rat hepatic stellate cells. Biochem Biophys Res Commun 359: 292-297.

KLOC, A., ZARATIEGUI, M., NORA, E. and MARTIENSSEN, R. (2008). Rna interference guides histone modification during the $s$ phase of chromosomal replication. Curr Biol 18: 490-495.

LI, C.F., HENDERSON, I.R., SONG, L., FEDOROFF, N., LAGRANGE, T. and JACOBSEN, S.E. (2008). Dynamic regulation of argonaute4 within multiple nuclear bodies in arabidopsis thaliana. PLOS Genet 4: e27.

LI, C.F., PONTES, O., EL-SHAMI, M., HENDERSON, I.R., BERNATAVICHUTE, Y.V., CHAN, S.W., LAGRANGE, T., PIKAARD, C.S. and JACOBSEN, S.E. (2006). An argonaute4-containing nuclear processing center colocalized with cajal bodies in arabidopsis thaliana. Cell 126: 93-106.

LI, F., GOTO, D.B., ZARATIEGUI, M., TANG, X., MARTIENSSEN, R. and CANDE, W.Z. (2005). Two novel proteins, dos 1 and dos2, interact with rik1 to regulate heterochromatic rna interference and histone modification. Curr Biol 15: 14481457.
LIPPMAN, Z. and MARTIENSSEN, R. (2004). The role of rna interference in heterochromatic silencing. Nature 431: 364-70.

LIU, J., HE, Y., AMASINO, R. and CHEN, X. (2004). Sirnas targeting an intronic transposon in the regulation of natural flowering behavior in arabidopsis. Genes Dev 18: 2873-2878.

LU, J. and GILBERT, D.M. (2007). Proliferation-dependent and cell cycle regulated transcription of mouse pericentric heterochromatin. J Cell Biol 179: 411-421.

MAISON, C., BAILLY, D., PETERS, A.H., QUIVY, J.P., ROCHE, D., TADDEI, A. LACHNER, M., JENUWEIN, T. and ALMOUZNI, G. (2002). Higher-order structure in pericentric heterochromatin involves a distinct pattern of histone modification and an rna component. Nat Genet 30: 329-334.

MALONE, C.D., ANDERSON, A.M., MOTL, J.A., REXER, C.H. and CHALKER, D.L. (2005). Germ line transcripts are processed by a dicer-like protein that is essential for developmentally programmed genome rearrangements of tetrahy mena thermophila. Mol Cell Biol 25: 9151-9164.

MATZKE, M., AUFSATZ, W., KANNO, T., DAXINGER, L., PAPP, I., METTE, M.F. and MATZKE, A.J. (2004). Genetic analysis of rna-mediated transcriptiona gene silencing. Biochim Biophys Acta 1677: 129-141.

MATZKE, M., KANNO, T., DAXINGER, L., HUETTEL, B. and MATZKE A.J. (2009). RNA-mediated chromatin-based silencing in plants. Curr Opin Cell Biol. [Epub ahead of print] DOI:10.1016/j.ceb.2009.01.025

MATZKE, M., KANNO, T., HUETTEL, B., DAXINGER, L. and MATZKE, A.J. (2007). Targets of rna-directed DNA methylation. Curr Opin Plant Biol 10: 512-519.

MAY, B.P., LIPPMAN, Z.B., FANG, Y., SPECTOR, D.L. and MARTIENSSEN, R.A. (2005). Differential regulation of strand-specific transcripts from arabidopsis centromeric satellite repeats. PLoS Genet 1: e79.

MELLO, C.C. and CONTE, D., JR. (2004). Revealing the world of rna interference. Nature 431: 338-342.

METTE, M.F., AUFSATZ, W., VAN DER WINDEN, J., MATZKE, M.A. and MATZKE, A.J. (2000). Transcriptional silencing and promoter methylation triggered by double-stranded rna. Embo J 19: 5194-5201.

MORRIS, K.V., CHAN, S.W., JACOBSEN, S.E. and LOONEY, D.J. (2004). Small interfering rna-induced transcriptional gene silencing in human cells. Science 305: 1289-1292.

MOTAMEDI, M.R., VERDEL, A., COLMENARES, S.U., GERBER, S.A., GYGI, S.P and MOAZED, D. (2004). Two rnai complexes, rits and rdrc, physically interact and localize to noncoding centromeric rnas. Cell 119: 789-802.

MURAKAMI, H., GOTO, D.B., TODA, T., CHEN, E.S., GREWAL, S.I. MARTIENSSEN, R.A. and YANAGIDA, M. (2007). Ribonuclease activity of dis3 is required for mitotic progression and provides a possible link between heterochromatin and kinetochore function. PLOS ONE 2: e317.

MURCHISON, E.P., PARTRIDGE, J.F., TAM, O.H., CHELOUFI, S. and HANNON G.J. (2005). Characterization of dicer-deficient murine embryonic stem cells Proc Natl Acad Sci U S A 102: 12135-12140.

NOMA, K., SUGIYAMA, T., CAM, H., VERDEL, A., ZOFALL, M., JIA, S., MOAZED D. and GREWAL, S.I. (2004). Rits acts in cis to promote rna interferencemediated transcriptional and post-transcriptional silencing. Nat Genet36: 1174 1180.

OKAMURA, K., BALLA, S., MARTIN, R., LIU, N. and LAI, E.C. (2008). Two distinct mechanisms generate endogenous sirnas from bidirectional transcription in drosophila melanogaster. Nat Struct Mol Biol. 15: 998

PAL-BHADRA, M., LEIBOVITCH, B.A., GANDHI, S.G., RAO, M., BHADRA, U., BIRCHLER, J.A. and ELGIN, S.C. (2004). Heterochromatic silencing and hp1 localization in drosophila are dependent on the rnai machinery. Science 303 669-672.

PARTRIDGE, J.F., DEBEAUCHAMP, J.L., KOSINSKI, A.M., ULRICH, D.L., HADLER, M.J. and NOFFSINGER, V.J. (2007). Functional separation of the requirements for establishment and maintenance of centromeric heterochromatin. Mol Cell 26: 593-602.

PARTRIDGE, J.F., SCOTT, K.S., BANNISTER, A.J., KOUZARIDES, T. and ALLSHIRE, R.C. (2002). Cis-acting DNA from fission yeast centromeres mediates histone h3 methylation and recruitment of silencing factors and cohesin to an ectopic site. Curr Biol 12: 1652-1660.

PELISSIER, T. and WASSENEGGER, M. (2000). A DNA target of $30 \mathrm{bp}$ is sufficient for rna-directed DNA methylation. Rna 6: 55-65. 
PETRIE, V.J., WUITSCHICK, J.D., GIVENS, C.D., KOSINSKI, A.M. and PARTRIDGE, J.F. (2005). Rna interference (rnai)-dependent and rnai-independent association of the chp1 chromodomain protein with distinct heterochromatic loci in fission yeast. Mol Cell Biol 25: 2331-2346.

PONTES, O., LI, C.F., NUNES, P.C., HAAG, J., REAM, T., VITINS, A., JACOBSEN, S.E. and PIKAARD, C.S. (2006). The arabidopsis chromatin-modifying nuclear sirna pathway involves a nucleolar rna processing center. Cell 126: 79-92.

PONTIER, D., YAHUBYAN, G., VEGA, D., BULSKI, A., SAEZ-VASQUEZ, J., HAKIMI, M.A., LERBS-MACHE, S., COLOT, V. and LAGRANGE, T. (2005). Reinforcement of silencing at transposons and highly repeated sequences requires the concerted action of two distinct rna polymerases iv in arabidopsis. Genes Dev 19: 2030-2040.

PULUKURI, S.M. and RAO, J.S. (2007). Small interfering rna directed reversal of urokinase plasminogen activator demethylation inhibits prostate tumor growth and metastasis. Cancer Res 67: 6637-6646.

QI, Y., HE, X., WANG, X.J., KOHANY, O., JURKA, J. and HANNON, G.J. (2006). Distinct catalytic and non-catalytic roles of argonaute4 in rna-directed DNA methylation. Nature 443: 1008-1012.

REINHART, B.J. and BARTEL, D.P. (2002). Small rnas correspond to centromere heterochromatic repeats. Science 297: 1831.

RIDDLE, N.C., LEUNG, W., HAYNES, K.A., GRANOK, H., WULLER, J. and ELGIN, S.C. (2008). An investigation of heterochromatin domains on the fourth chromosome of drosophila melanogaster. Genetics 178: 1177-1191.

ROBERT, V.J., SIJEN, T., VAN WOLFSWINKEL, J. and PLASTERK, R.H. (2005). Chromatin and rnai factors protect the $c$. Elegans germline against repetitive sequences. Genes Dev 19: 782-787.

SADAIE, M., IIDA, T., URANO, T. and NAKAYAMA, J. (2004). A chromodomain protein, chp1, is required for the establishment of heterochromatin in fission yeast. Embo J 23: 3825-3835.

SCHRAMKE, V., SHEEDY, D.M., DENLI, A.M., BONILA, C., EKWALL, K., HANNON, G.J. and ALLSHIRE, R.C. (2005). Rna-interference-directed chromatin modification coupled to rna polymerase ii transcription. Nature 435: 1275-1279.

SHIU, P.K., ZICKLER, D., RAJU, N.B., RUPRICH-ROBERT, G. and METZENBERG, R.L. (2006). Sad-2 is required for meiotic silencing by unpaired DNA and perinuclear localization of sad-1 rna-directed rna polymerase. Proc Natl Acad Sci U S A 103: 2243-2248.

SLOTKIN, R.K. and MARTIENSSEN, R. (2007). Transposable elements and the epigenetic regulation of the genome. Nat Rev Genet 8: 272-285.

SUGIYAMA, T., CAM, H., VERDEL, A., MOAZED, D. and GREWAL, S.I. (2005). Rna-dependent rna polymerase is an essential component of a self-enforcing loop coupling heterochromatin assembly to sirna production. Proc Natl Acad Sci US A 102: 152-157.

SUGIYAMA, T., CAM, H.P., SUGIYAMA, R., NOMA, K., ZOFALL, M., KOBAYASHI, R. and GREWAL, S.I. (2007). Shrec, an effector complex for heterochromatic transcriptional silencing. Cell 128: 491-504.

SVOBOdA, P., STEIN, P., ANGER, M., BERNSTEIN, E., HANNON, G.J. and SCHULTZ, R.M. (2004). Rnai and expression of retrotransposons muerv-I and iap in preimplantation mouse embryos. Dev Biol 269: 276-285.

SWERGOLD, G.D. (1990). Identification, characterization, and cell specificity of a human line-1 promoter. Mol Cell Biol 10: 6718-6729.

SWIEZEWSKI, S., CREVILLEN, P., LIU, F., ECKER, J.R., JERZMANOWSKI, A., AND DEAN C. (2007). Small RNA-mediated chromatin silencing directed to the 3 ' region of the Arabidopsis gene encoding the developmental regulator, FLC. Proc Natl Acad Sci USA 104: 3633-3638.

TAM, O.H., ARAVIN, A.A., STEIN, P., GIRARD, A., MURCHISON, E.P., CHELOUFI, S., HODGES, E., ANGER, M., SACHIDANANDAM, R., SCHULTZ, R.M. et al. (2008). Pseudogene-derived small interfering rnas regulate gene expression in mouse oocytes. Nature 453: 534-538.
TING, A.H., SCHUEBEL, K.E., HERMAN, J.G. and BAYLIN, S.B. (2005). Short double-stranded rna induces transcriptional gene silencing in human cancer cells in the absence of DNA methylation. Nat Genet 37: 906-910.

VERDEL, A., JIA, S., GERBER, S., SUGIYAMA, T., GYGI, S., GREWAL, S.I. and MOAZED, D. (2004). Rnai-mediated targeting of heterochromatin by the rits complex. Science 303: 672-676.

VERDEL, A. and MOAZED, D. (2005). Rnai-directed assembly of heterochromatin in fission yeast. FEBS Lett 579: 5872-5878.

VOLPE, T., SCHRAMKE, V., HAMILTON, G.L., WHITE, S.A., TENG, G., MARTIENSSEN, R.A. and ALLSHIRE, R.C. (2003). Rna interference is required for normal centromere function in fission yeast. Chromosome Res 11: 137-146.

VOLPE, T.A., KIDNER, C., HALL, I.M., TENG, G., GREWAL, S.I. and MARTIENSSEN, R.A. (2002). Regulation of heterochromatic silencing and histone h3 lysine-9 methylation by rnai. Science 297: 1833-1837.

WANG, S.W., STEVENSON, A.L., KEARSEY, S.E., WATT, S. and BAHLER, J. (2008). Global role for polyadenylation-assisted nuclear rna degradation in posttranscriptional gene silencing. Mol Cell Biol 28: 656-665.

WASSENEGGER, M., HEIMES, S., RIEDEL, L. and SANGER, H.L. (1994). Rnadirected de novo methylation of genomic sequences in plants. Cell 76: 567-576.

WATANABE, T., TOTOKI, Y., TOYODA, A., KANEDA, M., KURAMOCHIMIYAGAWA, S., OBATA, Y., CHIBA, H., KOHARA, Y., KONO, T., NAKANO, T. et al. (2008). Endogenous sirnas from naturally formed dsrnas regulate transcripts in mouse oocytes. Nature 453: 539-543.

WEINBERG, M.S., VILLENEUVE, L.M., EHSANI, A., AMARZGUIOUI, M., AAGAARD, L., CHEN, Z.X., RIGGS, A.D., ROSSI, J.J. and MORRIS, K.V. (2006). The antisense strand of small interfering rnas directs histone methylation and transcriptional gene silencing in human cells. Rna 12: 256-262.

WOOD, V.GWILLIAM, R.RAJANDREAM, M.A.LYNE, M.LYNE, R.STEWART, A.SGOUROS, J.PEAT, N.HAYLES, J.BAKER, S. et al. (2002). The genome sequence of schizosaccharomyces pombe. Nature 415: 871-880.

YANG, N. and KAZAZIAN, H.H., JR. (2006). L1 retrotransposition is suppressed by endogenously encoded small interfering rnas in human cultured cells. Nat Struct Mol Biol 13: 763-771.

YAO, M.C. and CHAO, J.L. (2005). Rna-guided DNA deletion in tetrahymena: An rnai-based mechanism for programmed genome rearrangements. Annu Rev Genet 39: 537-559.

YU, F., ZINGLER, N., SCHUMANN, G. and STRATLING, W.H. (2001). Methyl-cpgbinding protein 2 represses line-1 expression and retrotransposition but not alu transcription. Nucleic Acids Res 29: 4493-4501.

ZHANG, K., MOSCH, K., FISCHLE, W. and GREWAL, S.I. (2008). Roles of the clr4 methyltransferase complex in nucleation, spreading and maintenance of heterochromatin. Nat Struct Mol Biol 15: 381-388.

ZHANG, M.X., OU, H., SHEN, Y.H., WANG, J., WANG, J., COSELLI, J. and WANG, X.L. (2005). Regulation of endothelial nitric oxide synthase by small rna. Proc Natl Acad Sci U S A 102: 16967-16972.

ZHANG, X., YAZAKI, J., SUNDARESAN, A., COKUS, S., CHAN, S.W., CHEN, H., HENDERSON, I.R., SHINN, P., PELLEGRINI, M., JACOBSEN, S.E. et al. (2006). Genome-wide high-resolution mapping and functional analysis of DNA methylation in arabidopsis. Cell 126: 1189-1201.

ZHENG, X., ZHU, J., KAPOOR, A. and ZHU, J.K. (2007). Role of arabidopsis ago6 in sirna accumulation, DNA methylation and transcriptional gene silencing. Embo J 26: 1691-1701.

ZILBERMAN, D., GEHRING, M., TRAN, R.K., BALLINGER, T. and HENIKOFF, S (2007). Genome-wide analysis of arabidopsis thaliana DNA methylation uncovers an interdependence between methylation and transcription. Nat Genet 39: 61-69. 


\section{Further Related Reading, published previously in the Int. J. Dev. Biol.}

See our recent Special Issue Evolution \& Development, edited by Jaume Baguñà and Jordi García-Fernández at: http://www.ijdb.ehu.es/web/contents.php?vol=47\&issue $=7 / 8$

Two msh/msx-related genes, Djmsh1 and Djmsh2, contribute to the early blastema growth during planarian head regeneration

Linda Mannini, Paolo Deri, Vittorio Gremigni, Leonardo Rossi,

Alessandra Salvetti and Renata Batistoni

Int. J. Dev. Biol. (2008) 52: 943-952

Spa-1 regulates the maintenance and differentiation of human embryonic stem cells Young-Jin Lee, Hee-Young Nah, Seok-Ho Hong, Ji-Won Lee, Ilkyung Jeon, Jhang Ho Pak, Joo-Ryung Huh, Sung-Hoon Kim, Hee-Dong Chae,

Byung-Moon Kang, Chul Geun Kim and Chung-Hoon Kim

Int. J. Dev. Biol. (2008) 52: 43-53

A new gene in Drosophila melanogaster, Ravus, the phantom of the modifier of position-effect variegation Su(var)3-7

Marion Delattre, Anne Spierer, Nicolas Hulo and Pierre Spierer

Int. J. Dev. Biol. (2002) 46: 167-171

Functional analysis of the eye genetic network in planarian regeneration D Pineda, J Gonzalez-Linares, M Marsal, E Salo

Int. J. Dev. Biol. (2001) 45: S123-S124

Dynamic readjustment of parental methylation patterns of the 5'-flank of the mouse $\mathrm{H} 19$ gene during in vitro organogenesis

L Liang, C Kanduri, M Pilartz, K Svensson, J H Song, P Wentzel, U Eriksson and $\mathrm{R}$ Ohlsson

Int. J. Dev. Biol. (2000) 44: 785-790

Selective inhibition of gene expression by RNAi in chick embryos in ovo V Hernandez-Hernandez, J Fernandez, A Cardona, R Romero, D Bueno Int. J. Dev. Biol. (2001) 45: S99-S100

2006 ISI **Impact Factor $=3.577^{* *}$

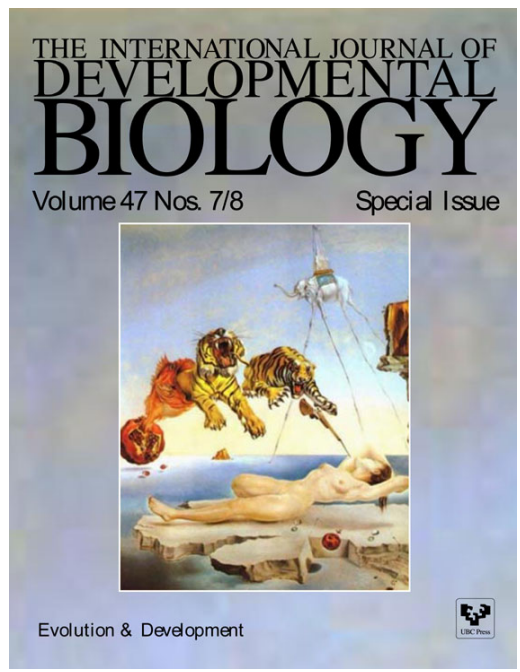

